\title{
Urban Health Challenges in Europe
}

\author{
Roderick J. Lawrence
}

\begin{abstract}
This article synthesizes diverse official reports, statistics, and scientific papers that present demographic, economic, environmental, and social trends impacting on the health and quality of life of citizens living in European cities. A literature review led to the identification of some key challenges including an aging society, migration flows, inequalities in health, global change, and risk behaviors that should be addressed in order to promote urban health. Other challenges, such as food production and consumption, are also relevant, but not included. Cities that have participated in one or more of the phases of the WHO European Healthy Cities Network have implemented a number of policies, programs, and measures to deal with the challenges discussed in this article. Some contributions are presented to illustrate how health and quality of life in urban areas can be promoted by local authorities.
\end{abstract}

KEYWORDS Aging society, Decentralization, Equity, European region, Health inequalities, Global change, Local authorities, Migration

\section{INTRODUCTION}

This article provides a broad overview of demographic, economic, environmental, and other societal challenges that impact directly or indirectly on health and quality of life in European cities. The main issues to be considered include how to promote health in an aging society, how to tackle health challenges stemming from migration flows, as well as inequalities and inequity across the whole socioeconomic gradient. The impacts of global change and risk behaviors will also be addressed. The article includes examples of how designated cities of the WHO European Healthy Cities Network (WHO-EHCN) have addressed these challenges by action research and policy implementation during the last 20 years.

Urban history indicates that Europe was the most urbanized region in the world for many centuries. In the mid-nineteenth century, London was the first city in the world to surpass one million residents. ${ }^{1}$ In 1910, those countries that constituted the European region had over half of the largest hundred cities in the world, whereas, in 2000 , this share had declined significantly such that only ten of the largest cities were located in the European region. Consequently, although European cities comprised about half of the world's urban population in 1910, their share had dropped to about $18 \%$ in 2000. These statistics show that urbanization trends, especially changes in the growth and geographical distribution of urban populations, have changed significantly in different regions of the world during the twentieth century. Today, the European region has many cities that have slow or marginal growth, whereas others have declining populations.

Lawrence is with the Institute of Environmental Sciences, Faculty of Social and Economic Sciences, University of Geneva, Carouge, Geneva, Switzerland.

Correspondence: Roderick J. Lawrence, Institute of Environmental Sciences, Faculty of Social and Economic Sciences, University of Geneva, Carouge, Geneva, Switzerland. (E-mail: roderick.lawrence@unige.ch) 
At the beginning of the twenty-first century, urbanization in the European region is so diverse that generalizations are difficult. One enduring feature of urban development is the dominance of capital cities including Berlin, London, Moscow, Paris, Rome, and of Vienna. The secondary role of manufacturing cities, including Birmingham, Leipzig, and the Healthy Cities of Manchester, Milan, and Torino, should be noted. Finally, there are a relatively large number of cities in all European countries with a population of around 100,000 citizens. There are no megacities in the WHO European Region.*

The European region is a term that is used in different ways. The WHO European Region comprises 53 member states stretching from the Atlantic shores of Ireland and Portugal in the West to shores of Siberia bordering the Sea of Okhotsk in the East. The UNECE region also comprises 53 countries, whereas the Council of Europe has 47 member countries, and the European Union currently includes 27 member states. The WHO European Region is the focus of the following analysis of the key challenges faced by cities at the beginning of the twenty-first century.

\section{CHALLENGES AND OPPORTUNITIES FOR LOCAL AUTHORITIES}

Data and information on cities and urban development in Europe have been collected over several decades. A number of documents have been published by the European Union, the World Bank, UN-HABITAT, the United Nations Population Division, and the United Nations Economic Commission for Europe. For example, in 1999, the Urban Audit collected data for 258 cities in the 27 member states of the European Union. A state of European Cities Report was published in 2007. The fourth assessment of Europe's Environment was published by the European Environment Agency in 2007. These kinds of sources, together with scientific studies published in peer-reviewed journals, have been used to write this article. It will discuss some key challenges including an aging society, migration flows, inequalities in health, global change, and risk behaviors that need to be addressed in order to promote urban health. Other challenges, such as food production and consumption, are also relevant, but not included.

\section{Demographic Trends in the European Region}

Over 870 million people live in the pan-European region. ${ }^{2}$ Over half of this population lives in Western and Central Europe, which is one of the most densely populated regions in the world. About $75 \%$ of the population of the 27 member states of the European Union lives in urban areas. Only about $2 \%$ of the labor force is now employed in the agricultural sector. ${ }^{2}$ Rapid urbanization during the twentieth century led to a high demand for housing, urban infrastructure, and community services including health care, education, and social services at the local level.

The size of national populations varies considerably across the European region. For example, whereas the Netherlands has a very high population density of about 400 persons $/ \mathrm{km}^{2}$, other countries, including Belarus (47 persons $/ \mathrm{km}^{2}$ ), Sweden $(21$ persons $/ \mathrm{km}^{2}$ ), and Norway (13 persons $/ \mathrm{km}^{2}$ ), have much lower densities. ${ }^{2}$ The region currently has the lowest rate of population growth of all regions in the world. ${ }^{3}$ Trends in population growth have varied over time and between countries.

\footnotetext{
"UN-HABITAT defines a megacity as one having a resident population over 20 millions.
} 
The population increase in countries of Central Asia, the Caucasus, and southeastern regions of Europe, including Turkey, has been greater than that in countries in Western and Central Europe. However, in general, since the 1990s, relatively high rates of population growth have ceased, and population growth has stagnated or declined in some countries, but not in others including the Netherlands, Portugal, Spain, and Turkey.

There have been significant changes to the age structure of the population as well as household size and composition during the last four decades. In most European countries, average household size is less than three persons per household. The incidence of divorce and cohabitation has increased since the 1960s. Today, the fertility rate is lower than the natural replacement level in many countries. The urban population is aging (see below). By 1995, the number of single-person households had increased dramatically, reaching over $50 \%$ of households in some European cities including Amsterdam, Frankfurt, and the Network cities of Copenhagen and Stockholm. ${ }^{3}$

\section{Aging Populations: Challenges and Opportunities}

The population of Europe is aging relatively quickly, owing to a number of social and cultural factors. The number of people between 65 and 80 years of age is expected to increase by about $40 \%$ between 2010 and 2030, while the number of people expected to live more than 80 years is predicted to double between 2010 and 2050. ${ }^{4}$ The European Commission has characterized this trend as a "demographic time bomb" because it is predicted to lead to a significant increase in the demand for health care and social welfare for elderly citizens who will become dependent. ${ }^{5}$ This interpretation assumes that, as people age, they also become less autonomous, owing to increased physical and mental disabilities. The World Health Organization has counteracted this negative interpretation by the positive concept of "active aging" which challenges the causal relation between old age and dependency. ${ }^{6}$ This positive concept is based on evidence that early and mid-life initiatives to promote physical activity, healthy nutrition, and social interaction can reduce disability and dependency in later life.

Healthy aging was one of the three core themes of phase IV of the WHO-EHCN. The activities of the 19 designated cities that collaborated in the Healthy Aging subnetwork are presented by Green in another article of this special issue. ${ }^{7}$ Green reviews how designated Network raised awareness of the status and role of elderly citizens, how they encouraged the elderly to manage their personal lives and also influence decisions that impact on their local community, how these cities have promoted built environments that are user friendly for the elderly, and how they have promoted access to both private and public services. These tangible initiatives reduce functional disability and dependency while promoting healthy aging. This positive contribution of healthy cities can be contrasted with the ongoing unproductive debate about institutional or domiciliary health care in the context of reducing public expenditure on social welfare.

The European Commission launched an action plan titled Information and Communication Technologies as one way to deal with the challenge of meeting the needs of increasing numbers of elderly citizens. These technologies can enable more efficient management and delivery of health and social welfare services provided; they are user friendly and account for those target groups with disabilities. Three key concerns related to the specific needs of the elderly are: (1) aging at work or staying active in the work force as long as possible, (2) aging in the community in order to 
reduce social isolation and promote intergenerational solidarity, and (3) aging at home in order to maintain personal autonomy, independence, and dignity.

\section{Attractive Cities: Shrinking Populations and Economic Activity}

Since the 1970s, population decline and renewal has become a concern for many European cities because this issue has a direct impact on revenues collected by local authorities from taxation. The trend is partly related to low fertility rates and increasing longevity. However, it also is influenced by migration by those who want a better quality of life (improved employment opportunities, housing markets, community services, microclimate, etc.) Following research in former East Germany, Herrschel concluded that, in the case of the Network city of Dresden, there is evidence of both the continued attractiveness of the city center as a place to live as well as a strong preference for living in the suburbs. Between 1993 and 1996, nearly 26,000 people left the city, and $43 \%$ moved to the newly developing suburbs. At the same time, some 20,000 people moved into the city, including 12,000 coming from outside Germany; 4,000 from West Germany; and 4,000 from rural areas of Southeast Saxony. ${ }^{8}$ The situation is similar in the Leipzig region surrounding the second largest city of Eastern Germany with a population of some 580,000. There, initial losses after 1990 have turned into gains since 1998. ${ }^{9}$ This process of reurbanization is being observed in other European countries including the UK.

The attractiveness of a city can be enhanced by local government policies, programs, and projects to improve and sustain the quality of life of citizens. Changes in population size and the role of the private sector in the local economy are crucial components of local conditions because they contribute to the financial capacity of the local authority. A city's attractiveness to a resident population and the business sector influences its autonomy and responsibility for action. Increases in revenue from the taxes of a growing population, especially residents in the higher income groups, as well as increases in income from business taxes, will strengthen the capacity of cities to implement policies and programs that promote and sustain the quality of life. In contrast, population losses and lack of new investments by the private sector will reduce the capacity of local authorities to define their own policies and programs independently from national initiatives. ${ }^{8}$ Local authorities need to define a strategy to promote the attractiveness of their city for private enterprises, cultural and sportive events, and residential living by a wide range of households. ${ }^{10}$

\section{Migration Flows and Urbanization}

Immigration is commonly characterized as population movement from poor to richer localities as well as from rural to urban areas. Migration flows in the European region are the most important cause of the current increase of the population in many European cities including the Network cities of Bologna, Geneva, Ljubljana, Manchester, and Vienna. ${ }^{11}$ There is a complex set of context-dependent factors-economic, geographical, political, and social—which help explain why population growth occurs in some cities while declining in others. Although macroeconomic factors may be crucial determinants of population growth and migration flows, political factors, including civil war, have played a crucial role in the European region both before and during the twentieth century, and they still do today.

The European region is both a recipient and source of migrants. The World Bank estimates that the region accounts for one third of all global emigration and immigration. ${ }^{12}$ Since the 1990 s, migration flows have increased. Several kinds of 
trends have been identified: first, permanent migration between countries, mainly for political or economic reasons. The Balkan countries are well-known examples following the disintegration of the former Yugoslavia. Second is permanent migration from rural to urban areas often following a shift from agricultural to other kinds of economies and the creation of new jobs in urban areas. Third is the seasonal migration of workers, especially those in the construction sector, as well as increasing numbers of retired persons who spend their leisure in coastal or rural areas.

Until 1989, migration flows in Eastern and Central Europe were strictly controlled movements within countries, except immediately after political upheavals (for example, in Hungary, in 1956; in Czechoslovakia, in 1968; and in Poland, in 1981). An extreme case is the Balkan region, following the disintegration of the former Yugoslavia. The United Nations estimates that about 1.8 million displaced persons, and over half a million refugees have moved from their homes. ${ }^{3}$ Since 1989 , the new political geography of the former Soviet Union has meant that this huge region should be reconsidered in terms of its distinct subregions comprising the Baltic States in the west, new independent countries of Central and Eastern Europe, including the division of former Czechoslovakia and Yugoslavia, as well as the Republics of Central Asia.

In those countries of the former Soviet Union with transition economies, in the year 2000, there were 25 cities with over one million residents. In that year, seven cities exceeded two million residents: Bucharest (two million), Tashkent (2.2 million), Warsaw (2.3 million), Kiev (2.5 million), Katowice (3.5 million), St. Petersburg (4.6 million), and Moscow (8.4 million). "Cities in these countries have experienced a rapid increase in population movements, owing to social and economic changes following the collapse of the centralized political system. Most migration flows are related to people seeking employment or asylum. Russia is the most important destination country in Eastern Europe, especially for migrants from the Republics of Central Asia that were part of the former Soviet Union. According to UN-HABITAT, in 2005, about 33 million people or more than $8 \%$ of the population of Russia and other Eastern European countries were migrants, and the vast majority of them lived in cities (see also footnote 2). Two of the three Baltic republics had the highest percentage of foreign population in 2000: $26 \%$ in Estonia, $25 \%$ in Latvia, and $9 \%$ in Lithuania. ${ }^{13}$

\section{European Cities in the Global Economy}

European cities have been the centers of economic growth for centuries. Financial investment and increasing employment opportunities have been the main drivers of urbanization since the Industrial Revolution. However, given the diversity of cities and different patterns of urban development in the WHO European region, the analysis of urbanization should be grounded on national and local data and information.

Today, the largest European cities are part of worldwide networks in a global economy. ${ }^{14}$ Their economies are strongly related to the service sector. The gross domestic product (GDP) of the WHO European region is equal to about $28 \%$ of global GDP. ${ }^{13}$ The term globalization refers not only to current world economic trends but also a strategy for development based on the privatization of former

\footnotetext{
"UN-HABITAT defines a megacity as one having a resident population over 20 millions.
} 
public services (such as water supply) and the liberalization of markets to promote the free flow of goods, finance, and information. ${ }^{15}$ Free trade is meant to abolish tariffs so that customers profit from lower prices. Exports from EU countries equal about $38 \%$ of their combined gross domestic product. ${ }^{16}$

The trends toward deregulation and trade liberalization impact on the behavior of multinational companies, especially on those that have operated within relatively protected markets. Some companies have initiated a series of microeconomic adjustments aimed at managerial and technological modernization. These processes were meant to increase all the levels of productivity, but they have not always had positive effects on employment. Instead, in many cities with relatively obsolete industrial structures, the increase in productivity and the shift from industrial toward tertiary employment has resulted in losses in formal employment.

An important trend observed in recent decades is the new territorial and competitive role of cities in the global economy. ${ }^{17}$ Instead of passively depending on macro- and microeconomic factors in movements related to globalization, local stakeholders have become more concerned about the potential competitive advantages of large cities and metropolitan regions. This trend has grown in parallel to changes in overall macro- and microeconomic frameworks in Europe and the USA since the 1970s and in other Asian and Latin American countries since the mid-1980s. Cities and metropolitan areas are increasingly engaged in new challenges in the region of local development income and employment generation without depending exclusively on national government initiatives.

Many cities in the European region have shown, by example, how economic growth is not dependent on high rates of urbanization or the large size of cities. Today, it is recognized that the competence and accountability of local and national governments are associated with coordinated urban and regional planning. Relatively small cities have been competing successfully with the largest European cities for new economic investments. ${ }^{18} \mathrm{~A}$ common approach in different cities has been establishing the right conditions for endogenous development using the local skills available in each city. The essence of these contributions has been the awareness that the mobilization of public and private actors and skills can permit the creative use of globalization. Simultaneously, this approach can also improve urban productivity, working conditions, and the quality of life of citizens. For example, community infrastructure, including coordinated public transport services, affordable housing markets, and efficient communication systems, are crucial features of the competitive status of European cities. Following specific examples, including the "Bilbao effect," elected officials and public administrators in other European cities should recognize the important role that their policies and programs can make irrespective of national initiatives.

\section{Poverty in European Cities}

Poverty and deprivation are two interrelated concepts with a direct impact on health. In order to deal adequately with these concepts, a distinction is commonly made between the predetermined factors (including genetics, age, and gender) and the variable factors (including income, living conditions, and lifestyle) that can have direct or indirect impacts on health and quality of life. Some of these factors can be moderated by local authority initiatives, as shown by the contributions of WHOEHCN Healthy Cities during the last 20 years.

Some European countries, including Denmark, Sweden, and the UK, have recorded increases in inequalities since the 1980s, partly owing to the liberalization 
of national economies, globalization, increased wage differentials, and relatively high levels of unemployment. ${ }^{19}$ Several studies show sustained socioeconomic inequalities in mortality in western European countries since the 1970 s. $^{20}$ Owing to the lack of coordinated data and information at the city level in many European countries, it is difficult to assess whether these inequalities have been dealt with effectively and especially since the 1990s. However, a coordinated research project funded by the European Commission in six countries (Denmark, England/Wales, Finland, Italy, Norway, and Sweden) has concluded that relative social inequality in mortality increased during the period between 1981-1985 and 1991-1995. ${ }^{21}$

During the period between 1991-1993 and 2005-2007, life expectancy at birth improved in all regions of the UK. However, the improvements varied between regions and cities, tending to favor the most prosperous. The biggest improvement in life expectancy occurred in the rich London Borough of Kensington and Chelsea with an additional 4.6 years for males and 3.1 years for females. In contrast, the smallest improvement for males of 3.3 years occurred in Scotland, while the smallest improvement for females of 2.3 years occurred in Wales. Consequently, in 2005, the Network city of Glasgow City has the shortest life expectancy at birth being 70.8 for males and 77.1 for females, whereas the highest life expectancy in that year was in Kensington and Chelsea with 87.8 years for females and 83.7 years for men. These official statistics show that the differences between life expectancy at birth for males and females decreased slightly during the period, whereas the differences in life expectancy for the populations in Glasgow and London increased.

Research on life expectancy at birth in Denmark has shown that increases have been less than in many other European countries, and that growing inequalities have also occurred between socioeconomic population groups. During the period 1975 to 2000, life expectancy for males increased 3.4 years (from 71.1 to only 74.5 years), while the increase during the same period for females was only 2.4 years (from 76.8 to 79.2 years). ${ }^{22}$ However, these statistical averages mask important socioeconomic differences based on education. Between 1981 and 2005 in Denmark, age- and gender-specific mortality rates for three levels of education show that, during the last 25 years, the social gap in life expectancy has widened, and those women with a low educational level have become increasingly disadvantaged.

\section{Urban Poverty: Increasing Social Exclusion}

Cities comprise what is termed the "urban advantage" which refers to a set of opportunities including access to amenities and services, including education, employment, health care, housing as well as leisure, and cultural activities. However, much evidence confirms that cities have relatively high levels of inequalities, partly because not all population groups have equal access to these amenities and services. $^{23}$ European cities are no exception. This article argues that inequalities in health and quality of life in European cities result from biases and inadequacies of market economies as well as the policy agendas of national and local governments. For example, substandard housing is the result of the ineffective regulation of private housing sector as well as inadequate housing and land policies guiding programs at both national and local levels. In general, public investments in the housing sector have declined in European countries since the early 1990s. ${ }^{24}$

There have been changes in the availability and types of employment, owing to shifts from manufacturing to the service sector in European cities. The 1990s was a decade of changing labor markets, job insecurity, and more precarious work contracts. The acquisition and merger of companies have led to the restructuring of 
corporate firms and large-scale worker redundancies. The difference between the wages of skilled and unskilled workers increased during the $1990 \mathrm{~s}^{25}$ In some countries, including France, Germany, and the UK, employee dismissal laws have been weakened. These changes mean that an increasing number of unskilled and manual workers have not found full employment. A growing share of the workforce is paid relatively low wages and is employed in precarious jobs. Young adults have been disproportionately affected by these trends which have contributed to increasing numbers of homeless youth.

The dissolution of the former Soviet Union had severe economic and social consequences. The reduction of state sector employment without the equivalent growth of employment in the private sector led to a decline in wages, pensions, and social security payments during a period of high inflation. This produced an increase in income inequalities, unemployment, and poverty. In 2002, about $46 \%$ of residents of the former Soviet Union and Eastern European countries had an income of less than US $\$ 4$ per day compared with about $10 \%$ of the population in western European countries." The UN-HABITAT found that the capital cities of Moscow, Sofia, Warsaw, Tallin, and Bishkek have fewer poor citizens than other cities in the same countries (see also footnote 3 ).

There is growing evidence of a relationship between unemployment and health status. Data show that relatively high levels of both urban poverty and poor health are concentrated in certain cities and also in specific urban neighborhoods of both Eastern and Western Europe. For example, national data from Sweden show that those persons, who have experienced repeated periods of unemployment (about 1.65 million or $30 \%$ of the population aged from 16 to 64 years), have suffered longterm illness. ${ }^{26} \mathrm{~A}$ study of urban health in three local government areas in London found that "the most significant indicators for an increase in ill-health or mortality from heart disease, respiratory disease, asthma, and tuberculosis were unemployment, being in a low social class, and living in overcrowded conditions." ${ }^{27}$ Mortality rates from all causes among residents aged 25 to 64 years are $40 \%$ higher in Glasgow than in the nearby city of Edinburgh. ${ }^{28}$ Loss of employment can be linked to a twofold increase in the risk of mortality from cancer and cardiovascular disease among men younger than 60 years. $^{29}$

\section{Vulnerable Groups}

Health inequalities are differences in the health status of population groups that result from differences in income, education, nutrition, housing, and employment conditions, as well as unequal access to health leisure and community services. Consequently, inequalities of professional status, income, housing, and working conditions are reflected in and reinforced by inequalities in health and well-being. "Equity" in health addresses barriers that unfairly restrict some people from achieving their full health potential, as Ritsatakis discusses in another article in this special issue. ${ }^{30}$

Inequalities have a disproportionate effect on particular ethnic groups. In the UK, for example, $70 \%$ of all ethnic minority residents lived in the 88 most deprived neighborhoods in the country. Research concluded that the ten most deprived neighborhoods had levels of unemployment as high as $25 \%$, whereas the ten least

\footnotetext{
"UN-HABITAT, State of the world's cities, trends in transition countries, urbanization, and metropolitization.
} 
deprived neighborhoods had less than $4 \%$ unemployment. ${ }^{31}$ In Britain, there are also strong inequalities in mortality rates from injury for children of different socioeconomic groups: boys less than 14 years of age in the lowest social class have a tenfold greater chance of dying from fire, falls, or drowning than those boys in the highest social class. ${ }^{32}$

Homelessness is increasing in the European region, disproportionately affecting adolescents, single people, lone parents, and the unemployed in many European countries. There are far-reaching economic, health, and other social consequences arising from the growing numbers of disadvantaged children, adolescents, and young adults. Suicide is a leading cause of death for young adults being among the first three causes of death of the population between 15 and 34 years of age. ${ }^{23}$ The incidence of tuberculosis in urban areas reflects wider social inequalities. In London, for example, tuberculosis is also 150 times more likely to be found among the homeless population. ${ }^{33}$

\section{Housing and Health: Renewed Challenges}

At the Fourth European Ministerial Conference on Environment and Health held in Budapest in 2004, housing and health were attributed a high priority. This decision by the Ministers of Environment and Health from more than 50 European countries reflected and reinforced a growing concern about the health status of residents, especially those living in urban areas. The reasons for this concern are supported by a growing amount of data and information about rapid urbanization; increasing environmental, social, and economic problems; and the health and well-being of specific social groups. ${ }^{34}$

The layout, design, and maintenance of residential environments should meet the requirements of all groups of the population including the increasing number of people with special needs, especially the most vulnerable in society. These include the homeless, a group that comprises an increasing number of adolescents and young adults in industrialized countries; the elderly who need domiciliary care; people with disabilities, who require easy access to and within housing units; single-parent households that may need access to special child care services; and refugees and migrants that have specific cultural customs in and outside their housing unit that should be accommodated. All the requirements of people with special needs have rarely been addressed by the private housing sector, and municipal housing programs have played an important contribution to provide these needs since the public health movement and the housing reform movement during the nineteenth century in European cities. ${ }^{35}$ Today, local authorities are pioneering design guides ${ }^{36}$ and programs for both new construction and retrofitting of the existing housing stock to improve living conditions and the health of vulnerable occupants. ${ }^{37,37}$

\section{Global Change: Important Health Challenges}

Over many centuries, humans have adapted their habitat and way of life to the most diverse climatic conditions. Human societies will need to adapt to ongoing and future global changes including climate change, desertification, and loss of biodiversity if they are to sustain human civilizations. The process of adaptation will incur significant problems that will influence their survival. European cities, including Oxford, Prague, Venice, and the Network city of Dresden, have suffered repeated flooding in recent years, following extreme weather conditions. These kinds of events are predicted to increase in the future. A rise in sea level will impact 
on European cities including Amsterdam, London, and the Healthy Cities of Copenhagen and Rotterdam.

Warmer winters have already enabled tick species including Ixodes ricinus, a carrier of Lyme disease, to extend its habitat in European countries. ${ }^{39}$ Urban and suburban development may be associated with new diseases. The World Health Organization noted that not less than 20 new disease-causing organisms have been identified during the last two decades. One of these is known as Legionnaires' disease, and it is explicitly related to living and working conditions in buildings, especially those in cities. Room humidifiers, air ventilation systems, and cooling towers, as well as hot and cold water supply ducts, have been found to nurture Legionella pneumophila, the bacterium which can be transmitted through the indoor environment or discharged into the immediate vicinity of the building. ${ }^{40}$

The expansion of cities into their hinterlands, including the construction of roads, water reservoirs, and drains, together with land clearance and deforestation, can effect drastic changes to landscapes and ecosystems that may increase health risks. Natural foci for disease vectors may become entrapped within the suburban extension where new ecological niches may develop. Within urban areas, disease vectors may adapt to new habitats and introduce new infections to spread among the local population. Anopheline mosquitoes generally shun polluted water; yet, Anopheles stephensi, the principal vector for urban malaria, is also reported in the Eastern Mediterranean region to have adapted to survive in the urban environment, and other species of anophelines have also adapted to breed in swamps and ditches surrounding urban areas in Turkey.

Cities also create "islands of heat" with higher ambient temperatures than their hinterlands. Excessive heat has a direct impact on morbidity and mortality, especially among elderly and frail citizens who are at higher risk of dying from cardiovascular or respiratory diseases. In contrast, less severely cold winters, recorded in British and southern European cities for many decades, will reduce excess winter mortality. ${ }^{41}$

The scientific discourse, the political negotiations, and the media coverage of global change have strongly delimited debate to deal with the loss of habitat of specific species (e.g., polar bears in the Arctic region), whereas much less attention has been given to loss of human habitats. This shortcoming has been recently addressed by the Global Humanitarian Forum. ${ }^{42}$ This contribution underlines that global change, especially climate change, has a human dimension, and that it already poses a serious threat to the health and livelihood of huge numbers of people. The forum argues that the most appropriate way of dealing with uncertain impacts of these kinds of global challenges is by instigating efficient local counter measures. These measures can be effective if based on the principles of healthy urban planning, a core theme of phase IV of the WHO-EHCN. ${ }^{43}$

Another key challenge for contemporary cities is noise. Studies of the effects of noise on health and well-being indicate that the outdoor level of noise should not exceed a daytime Leq (equivalent sound pressure level) of $65 \mathrm{~dB}(\mathrm{~A})$. Residential areas exposed to noise levels between Leq $55 \mathrm{~dB}(\mathrm{~A})$ and $\mathrm{Leq} 65 \mathrm{~dB}(\mathrm{~A})$ are undesirable, and exposure to noise levels above Leq $75 \mathrm{~dB}(\mathrm{~A})$ is unacceptable because it can cause loss of hearing. ${ }^{44}$ Today, many European cities have ambient noise exceeding these levels. About 450 million persons (equal to $65 \%$ of the population) are exposed daily to ambient noise levels above $55 \mathrm{~dB}(\mathrm{~A})$; around 113 million (about $17 \%$ of the population) are exposed to ambient noise levels above Leq $65 \mathrm{~dB}(\mathrm{~A})$, and about 9.7 million citizens are exposed to high noise levels above 
$75 \mathrm{~dB}(\mathrm{~A})$. The main sources of acoustic nuisances are road, rail and air traffic, recreational activities, and industry. There is a growing amount of evidence that road traffic noise is the most widespread source of nuisance in European cities. In large European cities, it is estimated that the number of inhabitants exposed to unacceptable levels of noise is two or three times greater than national averages. ${ }^{13}$

\section{PROMOTING URBAN HEALTH}

The nation state has been challenged. On the one hand, its macroeconomic apparatus is less effective, partly due to the size and instability of massive flows of financial capital at the global level. On the other hand, given the global transformation toward more democratic and diversified local communities, national governments have been complemented by local and metropolitan systems of governance that are closer to local constituencies. Since the $1990 \mathrm{~s}$, decentralization has also become a major trend around the world. ${ }^{45}$ Today, national governments have less influence on housing, urban planning, and the local urban economy than they did two decades ago when most decisions about urban development were made at the national level. Decentralization or devolution was common in the 1990s, applying the principle of subsidiarity endorsed by the United Nations Conference on Environment and Development in Rio de Janeiro in 1992. However, decentralization can only be effective if the new roles and responsibilities of local authorities and municipal services are financially supported by the transfer of appropriate resources from the national to the local level.

While there are important variations between countries, in general, power and management have often been decentralized to the local level according to the principle of subsidiarity. Local authorities have increasingly assumed new roles beyond the mere management of urban services (such as housing, basic sanitation, education, and health services). The entrepreneurial dimension of public urban management (as reflected in the rise of strategies and employment generation, local economic development, and poverty alleviation) has become a prominent feature of the new agenda of local authorities. This trend has been reinforced by the creation or strengthening of community associations and networks.

The structure of local authorities in countries with national and local democracies usually includes a representative council elected by voters. This council makes policy decisions, whereas an executive board implements these decisions. The relationship between the council and the executive board varies between countries with different political regimes as well as between cities in the same country. The size of the council and the executive board is also variable. The most common feature around the world is that cities have a head executive who is frequently called the mayor. Mayors of cities have a unique leadership position that is crucial to the role local authorities can play in local economic development, environmental protection, housing provision, and health promotion. This role not only addresses local issues but also broader concerns including the global challenges of climate change, financial debts, and population health. The unique role and responsibility of mayors have been explicitly taken into account during all phases of the WHO-EHCN.

\section{SYNTHESIS}

Urban development policies and programs should explicitly acknowledge and address equity and equality. For example, conflicts exist between car-owning 
middle- and upper-class citizens and lower-income citizens who cannot afford to own a car. This conflict concerns the allocation of public funds and land for roads and car parking. Middle- and upper-class citizens expect larger and better quality roads as well as more low-cost parking spaces. Money spent on roads and car parking uses public funds that could be used for public transport, pedestrian walkways, and cycle routes. The conflict is difficult to resolve because it is not easy to define which public investment is better. In choosing among alternative expenditures, a primary goal ought to be the reduction of inequalities. Local authorities can ensure that their decisions promote the public good rather than private interests. While it is unrealistic to achieve income equality in market economies, it is realistic to promote the quality of life of citizens by ensuring access to education, leisure facilities, health care, community parks and gardens, and public transport.

\section{Learning from the Past}

Lessons could be learned from the historical development of the public health reform movement that began in Great Britain in the mid-nineteenth century, following rapid urban population growth, industrialization, the concentration of poverty in cities, and the propagation of infectious diseases. The compound problems of unsanitary housing, lack of a supply of safe water, ineffective disposal of sewage and solid waste, and inequality in health were tackled by devolving responsibility and authority to local municipalities in 1866 . The important role of local public administrations should be remembered at the beginning of the twentyfirst century when neoliberalism seems to have replaced state initiatives in many countries. Public health interventions should be emphasized, including housing for households with special needs; training the unemployed for reinsertion in the job market; coordinated solid waste disposal, sewerage and water services; and affordable health care services. In many countries today, including those in the former USSR, local public administrations lack the human and financial resources to counteract the conditions in cities that adversely affect health and well-being.

\section{CONCLUSION}

In 1994, at the Second European Conference on Environment and Health held in Helsinki, urban health was attributed a high priority for the first time. This decision by ministers responsible for the environment and health from 51 European countries reflects and reinforces a growing concern worldwide about the health status of residents in urban areas. Some of the reasons for this concern can adversely affect health and well-being. Until the 1990s, these problems were generally tackled by national policies and resource allocation. However, this custom has changed substantially since the 1990s; these national roles and responsibilities were decentralized to local authorities. These authorities have been delegated an increasingly important responsibility to define and implement policies and programs that promote health. The achievements of the WHO-EHCN underline the critical role of city governance. In 2010, World Health Day focused on urbanization and health. A campaign "1000 cities-1000 lives" provides numerous examples of how cities in and beyond Europe have assumed the challenges of addressing urban health. Hidden Cities, the report of WHO/UN-HABITAT concludes with a question: "The future of our urban world has yet to be realized, but brings both a price and a 
promise. To what extent, we will pay the price, as opposed to fulfilling the promise, is in our hands?" 23

\section{REFERENCES}

1. Bairoch P. Cities and economic development: from the dawn of history to the present. London: Mansell; 1988.

2. Union E. State of European Cities Report: adding value to the European Urban Audit. Brussels: EU; 2007.

3. Nations U. World urbanization prospects: the 2005 revision. New York: UN; 2006.

4. Commission of European Communities. Ageing well in the information society: an 2010 initiative action plan on information, and communication technologies and ageing. Brussels. EU COM 332 final; 2007

5. European Commission. Confronting demographic change: a new solidarity between the generations. The green paper on demographic changes. Brussels: European Commission; 2005.

6. World Health Organization. Active ageing: a policy framework. Geneva: WHO; 2002.

7. Green G. Age friendly cities of Europe. Journal of Urban Health (2012). harmonise

8. Herrschel T. Population shifts and local democratic representation in Eastern Germany. GeoJournal. 2000; 50: 213-233.

9. Kabisch N, Haase D, Haase A. Evolving reurbanisation? Spatio-temporal dynamics as exemplified by the East German city of Leipzig. Urban Studies. 2010; 47(5): 967-990.

10. Scott AJ. Creative cities: conceptual issues and policy questions. Journal of Urban Affairs. 2006; 28: 1-17.

11. Turok I, Mykhnenko V. The trajectories of European cities, 1960-2005. Cities. 2007; 24 (3): 165-182.

12. Bank W. Global economic prospects: managing the next wave of globalisation. Washington DC: World Bank; 2007.

13. European Environment Agency. Europe's environment: the fourth assessment. Copenhagen; 2007.

14. Organization of Economic Cooperation and Development. Competitive cities in a global economy. Paris: OECD; 2006.

15. Lo Fu-chen L, Yeung Y, eds. Globalization and the world of large cities. Tokyo: United Nations University Press; 1998.

16. Nations U. Human development report 1997. New York: UN; 1997.

17. Begg I, ed. Urban competitiveness: policies for dynamic cities. Bristol: Policy Press; 2002 (second edition 2004).

18. Lawrence R, Fudge C. Healthy cities in a global and regional context. Health Promotion International. 2009; 24(S1): i11-i18.

19. Organization for Economic Cooperation and Development. Integrating distressed urban areas. Paris: OECD; 1998.

20. Mackenbach J. The persistence of health inequalities in modern welfare states: the explanation of a paradox. Social Science \& Medicine. 2012; 75: 761-769.

21. Mackenbach J, Bos VO, Andersen O, et al. Widening socioeconomic inequalities in mortality in six Western European countries. International Journal of Epidemiology. 2003; 32: 830-837.

22. Bronnum-Hansen H, Baadsgaard M. Increasing social inequality in life expectancy in Denmark. European Journal of Public Health. 2007; 17(6): 585-586.

23. WHO/UN-HABITAT. Hidden cities: unmasking and overcoming health inequalities in urban settings. Geneva: World Health Organization; 2010.

24. Love J, O'Brien J, eds. Regional surveys of the world, Western Europe 2003. 5th ed. London: Europa Publications; 2003.

25. World Bank. Entering the 21st century: world development report 1999/2000. Washington DC; 2000. 
26. Sweden, National Board of Health and Welfare. Social report 1997. Stockholm; 1997.

27. Langdon M. Intra-urban health differentials in London: urban health indicators and policy implications. Environment and Urbanization. 1996; 8(2): 119-128.

28. Watt G, Ecob R. Mortality in Glasgow and Edinburgh: a paradigm of inequality in health. Journal of Epidemiology and Community Health. 1992; 46: 498-505.

29. Morris J, Cook D, Shaper A. Loss of employment and mortality. British Medical Journal. 1994; 308: 1135-1139.

30. Ritsatakis A. Equity and the social determinants of health in European cities. Journal of Urban Health. harmonise with Special Supplement (2012)

31. United Kingdom, Office of the Deputy Prime Minister. Changing neighbourhoods, changing lives: the vision for neighbourhood renewal. London; 2003.

32. World Health Organization Regional office for Europe. The social determinants of health: the solid facts. 2nd ed. Copenhagen: WHO; 2003.

33. Kumar D, Citron K, Leese J, Watson J. Tuberculosis among the homeless at a temporary shelter in London: report of a chest $\mathrm{x}$ ray screening programme. Journal of Epidemiology and Community Health. 1995; 49: 629-633.

34. World Health Organization. Large analysis and review of European housing and health status. http://www.euro.who.int/Housing/lares/20080403_1. Accessed on th July 2010.

35. Lawrence R. Housing and health: a way forward. Built Environment. 2005; 31: 315-325.

36. Omoboni GO. Older persons housing design: a European good practice guide. Brighton \& Hove: Brighton \& Hove City Council; 2007.

37. Warwick School of Law \& the Building Research Establishment. Linking housing conditions and health. Building Research Establishment, Watford UK; 2010.

38. Gilbertson J, Green G, Ormandy D. Decent homes, better health: Sheffield decent homes, health impact assessment. Sheffield: Sheffield Hallam University; 2006.

39. Harris Ali S, Keil R, eds. Networked disease. Oxford: Blackwell; 2008.

40. World Health Organization. Removing obstacles to healthy development. Report on infectious diseases. Geneva: WHO; 1999.

41. Kalnay E, Cai M. Impact of urbanization and land-use change on climate. Nature. 2003; 423: 528-531.

42. Global Humanitarian Forum. The anatomy of a silent crisis. Geneva; 2009.

43. Barton H, Grant M, Guise R. Shaping neighbourhoods for local health and global sustainability. 2nd ed. London: Routledge; 2010.

44. Stansfeld S, Brown B, Haines M. Noise and health in the urban environment. Reviews on Environmental Health. 2000; 15: 43-82.

45. Cheema S, Rondinelli D, eds. Decentralization and development: policy implementation in developing countries. Beverly Hills: Sage; 2007. 